\title{
Assessing the Influence of Greenery on the Behaviour of Road Users ${ }^{1}$
}

\author{
Karin Ausserer $^{a}$, Ralf Risser $^{b}$ \\ ${ }^{a}$ FACTUM OG,e-mail:karin.ausserer@factum.at \\ ${ }^{b}$ FACTUM OG,e-mail:ralf.risser@factum.at; www.factum.at
}

\begin{abstract}
The share of active mobility in traffic walking and cycling - can be increased by enhancing of the urban vegetation; this is the core assumption of the Austrian project "GoGreen". The main objective of this research project was to elaborate criteria of the roadside greenery that need to be incorporated into the planning of urban and street spaces, and finally implemented in order to create a highly aesthetic and stimulating atmosphere in public spaces. In addition to literature studies, qualitative methods (expert interviews, focus groups) and quantitative methods (street surveys) were used in this project to identify the needs and wishes of the residents. Subsequently, internal and external workshops helped to design evaluation criteria and recommendations for ordinary measures for promoting and supporting active mobility. In this paper, we focus on the street surveys that allow a glimpse on how citizens perceive the relationship between appropriately set urban vegetation, with respect to safety and attractiveness among other things, and its potential to motivate (more) citizens to walk (more).
\end{abstract}

KEYWORDS: urban greenery; active mobility; life quality; road user behaviour

\section{INTRODUCTION}

The desire for more green areas in urban environments is mentioned in several studies that investigate the needs of vulnerable road users (see e.g. Wunsch et al. 2007, Ausserer et al. 2009, Ausserer et al. 2014).

1 The project GoGreen was sponsored by the Austrian Research Promotionx Agency FFG and carried out by FACTUM Chaloupka \& Risser OG in cooperation Mira Kirchner, MK Landschaftsarchitektur e.U
International research, as well, showed that attractive design and equipment of roads, streets and places is one precondition for inciting people to walk instead of using the car for very short distances $(<1 \mathrm{~km}$; Gehl et al. 2013, Hancrenci 2013, Bowler et al. 2010, Zheng et al. 2014, de Vries et al. 2013, Krekel et al. 2015). In order to promote active and safe mobility, a useful and functional infrastructure together with the attractive design of open spaces, easily accessible and appreciated by the city's residents, are required. Providing green areas in the public space is one way to enhance attractivity. Design measures include compound types of green vegetation in the streets and the creation of recreational areas in public open spaces which have effect on many societal, social, ethnic and microclimatic factors. In the project GoGreen that was financed by the Austrian Ministry of Transport, Innovation and Technology the relation between active mobility and the provision and character of green areas was analysed in more detail. The goal of the project was to develop policy criteria to be applied in connection with road and transport planning in order to generate a public space that would motivate (more) people to walk (more), which would have positive effects for both public health and the environment. Green spaces would play an important role in this connection. The questions to be answered are: Where should green areas be placed, and how should they be designed in order to support active mobility?

\section{Functions of Urban Greenery}

There are various studies that outline the functions of urban greenery. Even though these studies do not explicitly refer to the positive effects of greenery they underline the link between road side greenery and mobility. Some of these functions are:

Climate function for the micro and meso climate: Urban greenery helps to avoid "heat islands" as 
it cools and provides shade (see Bowler et al 2011, Mursch \& Radgruber 2009, Ehmayer 2015). In addition, it improves the air quality (see Nowak et al 2006). These are important aspects when walking or cycling in the city.

Social function: Urban greenery has a positive impact on "community relations" and social cohesion. Social interaction and sociality promote the feeling of security and familiarity (e.g. Dinnie et al. 2013, Arnberger \& Eder 2012, Peters et al. 2010).

Recreation - Health function: Urban greenery not only supports social contacts, but has a positive effect on the physical and psychological well-being, too. Studies underline that the presence of greenery helps to relieve stress and encourages people to be outdoors (e.g., Tyrväinen et al. 2014, Han et al. 2013, Van der Berg et al. 2007)

Comfort \& Safety function: Urban greenery has a protective function (protection against rain and sun), an aesthetic function and a separating function. The latter is valid for avenue trees, lawn strips and patches of flowering that separate cars from pedestrian facilities (e.g. Adkins et al. 2012, Knoflacher 1996).

\section{METHODS AND PROCEDURE}

In a first step, national and international examples of best practice were searched for and summarised. Their potentials for application in an Austrian context were assessed. After that, the needs and wishes of inhabitants of Vienna were analysed with the help of a mixed methods combination. Qualitative methods - expert interviews, focus-group interviews and behaviour observations - were applied to identify aspects that would reflect what is of interest to the citizens. Quantitative methods - in this case road-side surveys - were applied to measure the distribution of those aspects in selected populations. Finally, suggestions for measures to enhance the introduction of green areas viz. to adapt and improve the design and the quality of such areas were developed in the frame of workshops with experts and citizens:

\section{Literature Analysis}

The literature analysis incorporated an internet research accompanied by expert talks with colleagues, in order to get an overview of the state of the art and of national and international good practice examples with respect to greenery projects in various urban areas.

\section{Qualitative interviews: expert interviews, focus group interviews}

13 interviews with experts - landscape architects, traffic planners, psychologists, representatives of Viennese authorities, and representatives of the Austrian Ministry of Transport, Innovation and Technology and three focus group interviews with heterogeneous groups of road users were carried out. In addition, indepth interviews with two ten-year-old children and four elderly people (80+) were conducted, as these age groups were not represented in the focus groups. These interviews gave an overview of requirements and needs of road users with respect to green infrastructure.

20 persons took part in the focus group interviews, 10 female and 10 male participants. One focus group consisted of 9 teenagers between 14 and 17 years of age. The participants in the other focus groups $(n=11)$ were aged between 20 and 75 years. The sample included walkers, cyclists, public transport users and car drivers. The focus groups lasted between $1 \frac{1 / 2}{2}$ and 2 hours.

Expert interviews and focus group interviews were used to gather relevant aspects connected to the subject of the study. With the help of these methods it is made sure that as many relevant issues and questions as possible are tackled in the frame of quantitative surveys to follow. The interviewers followed guidelines that were elaborated on basis of the literature study. The interviews were partly recorded and transcribed and partly journalised. The answers of the experts and focus group participants were anonymised and summarised per question. The results of these steps were used as a basis for the development of the quantitative survey instruments:

\section{Quantitative verbal data: Surveys}

Ten interviewers were trained and instructed for questioning. Then they carried out road-side surveys in all 23 districts of Vienna in November 2015. The weather was good at that time and the work could be done without much interruptions.

In total, 414 face-to-face standardised road-side surveys were carried out, with focus on the relation between green infrastructure and active mobility. Their results should display the residents' wish and willingness to participate actively in the designing of the public space. Furthermore, 200 face-to-face road-side surveys were conducted in which two streets in Vienna - one with and one without greenery - were compared according to criteria such as 'attractiveness' and 
'subjective feeling of safety'. The questionnaires for these surveys were developed in an iterative process, on the basis of the expert and focus group interviews, where a relationship between subjective safety and attractiveness was postulated. The interviewers were trained before questioning people on the road.

For the 414 interviews quota sampling was used according to age, gender and the place of living. The participants were between 14 and 92 years of age ( mean $=41,19 \&$ standard deviation $=19,15$ years $)$. In total, 212 female and 202 male persons took part in the interviews. Different types of road users were represented in the sample: $39 \%$ regular walkers, 33\% regular public transport users, $10 \%$ regular cyclists and $18 \%$ regular car drivers ("regular" = those who use the transport mode at least three times a week). The interviews took place in November 2015 under good weather conditions.

\section{Comparison study: Road side interviews}

The goal of this working step was to get a first impression of how attractiveness and subjective safety of pedestrians may be affected by one important traffic characteristic, namely car speed, and by greenery. The comparison study took place in two inner city streets of Vienna:

- Lerchenfelder Straße (LS): an arterial street running through the $7^{\text {th }}$ district of Vienna, traversable in both directions; parking lanes on both sides and tram tracks in the middle of the street in both directions, maximum speed $50 \mathrm{~km} / \mathrm{h}$, numerous shops, pubs and restaurants, pavements appr. 2,5 m wide, greenery (trees/some shrubs) on one side of the street (figure 1).

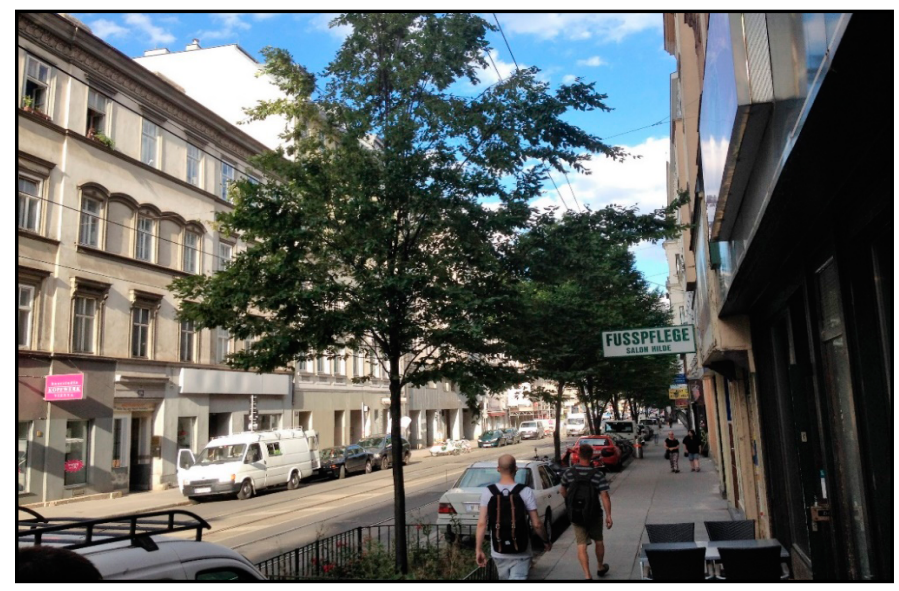

Figure 1: Lerchenfelderstraße

(C)Factum
- Neustiftgasse (NG): an arterial street in the 7th district, parallel to Lerchenfelderstraße; it is a one-way street, parking lanes on both sides, one lane for cars and one for buses, maximum speed $30 \mathrm{~km} / \mathrm{h}$, a few shops, pubs and restaurants, pavement appr. $2 \mathrm{~m}$ wide, no greenery (figure 2).

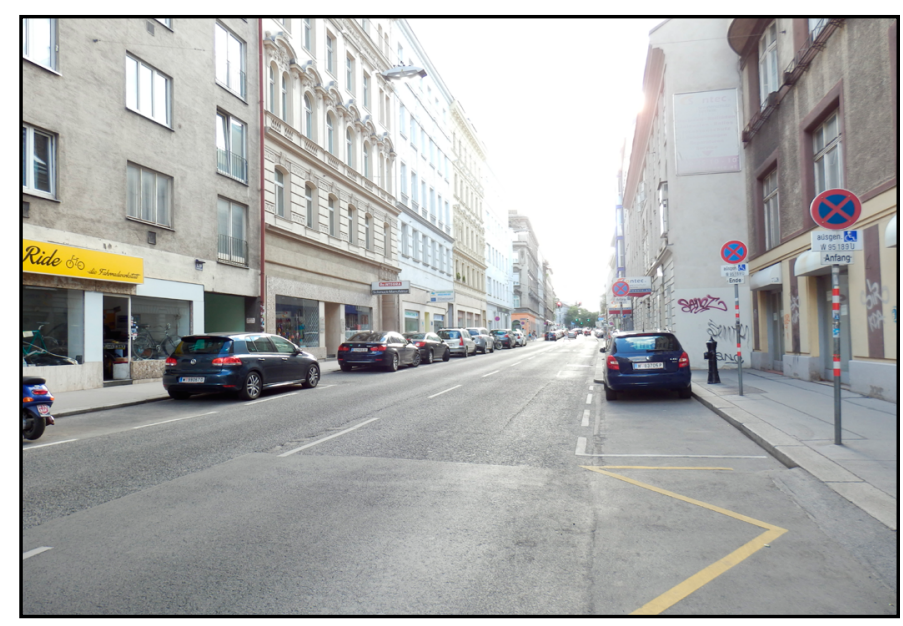

Figure 2: Neustiftgasse

(C)Factum

In each of these two streets 100 personal roadside interviews were carried out between June and July 2016. The interviews took place in July 2016 under good weather conditions. Quota sampling was used according to gender and age. In the questionnaire, statements concerning subjective safety and attractiveness of the two roads were presented and the questioned persons should answer on 5-step Likert-scales whether they agreed with these statements or not. $47 \%$ female and $53 \%$ male filled in the questionnaire. The interviewees were aged between 13 and 90 (mean $=41,3$ years, $S D=15,82) .40 \%$ were regular walkers, $35 \%$ regular public transport users, $13 \%$ regular cyclists, $12 \%$ regular car drivers. All participants lived in Vienna and the majority of the respondents were familiar with the street/s.

In the following the main results of the standardised surveys (Quantitative verbal data and Comparative study) will be outlined, with references to the preparative qualitative steps where suitable or necessary:

\section{RESULTS}

\section{Link between active mobility and greenery}

The experts considered the interrelation between mobility and greenery undisputable. Greening would have a lot of advantages according to them. The fol- 
lowing aspects were mentioned which have a reference to literature, as well:

- Greening makes areas "human": Greening creates a distance to car traffic: „Within a 30-40m of cross section of the street a human being without a tree feels lost" (expert interview, traffic planner); greening makes people feel comfortable.

- Noise protection: Objectively greening has only a low noise-protection potential but in a subjective way it influences the feeling of noise protection.

- Shadowing: Greening protects against sun and gives shade to pedestrians and cyclists.

- Perception of seasons: Greening enables to register seasons more consciously. Thus, the contact to nature does not vanish. "There is also room for insects and small crawlers" (expert interview, traffic planner).

- Physical and psychological well-being: According to the experts, greenery helps to relax, makes the public space livelier, and has a positive effect for well-being. It stimulates the wish for staying outside.

The results of the first survey $(n=414)$ underlined the importance of greenery for active mobility, as well (see table 1).

- $75 \%$ of all respondents consider urban greenery as (very) important for their daily walks. Only $7 \%$ do not value greenery and $18 \%$ are indifferent. People who already walk and cycle a lot and elderly people appreciate urban greenery more than others.

- $64 \%$ would like to have more trees and plants in Vienna.

- $46 \%$ consider additional green areas more important than car parks. People who are used to walk a lot (significantly more than the average) often approve this statement, unlike those who use the car every day.

- $46 \%$ would walk more often if the city was greener. These data support the finding of the focus group interviews that greenery is possibly the most important incentive for walking.

- $31 \%$ would cycle more often if the city was greener.

Even though greenery motivates people to walk, the interviewees are less willing to make detours just to reach a "green-route" (35\% would make a detour). Elderly people, women and those who walk often are more likely to make detours.

\section{Experiences in the public space}

In the focus group interviews the participants were asked to describe an attractive pedestrian route. The main characteristics of an attractive pedestrian route were: low car traffic; trees that provide shade and separate the pavement from the roadway; benches where you can sit and rest and watch the street or the surroundings. In the survey we asked what traffic characteristics are experienced as "usual" in public spac-

Table 1: Opinions with respect to greenery; Question: How much to you agree to the following statements? Agree - Agree mostly - neither nor - do not agree mostly - do not agree; the categories "agree" and "mostly agree", and "do mostly not agree" and "do not agree" are summarised.

\begin{tabular}{lccc}
\hline Statement & Agree (mostly) & Neither nor & Do not agree (mostly) \\
\hline For me greenery is important on all my ways in my everyday mobility & $75 \%$ & $18 \%$ & $7 \%$ \\
There should be more trees in Vienna & $64 \%$ & $27 \%$ & $9 \%$ \\
Additional greenery is more important than car parks & $46 \%$ & $27 \%$ & $27 \%$ \\
I will walk more often, if the city is greener & $46 \%$ & $17 \%$ & $37 \%$ \\
I will cycle more often, if the city is greener & $31 \%$ & $14 \%$ & $55 \%$ \\
On my everyday routes I choose mainly green routes & $49 \%$ & $21 \%$ & $44 \%$ \\
On my everyday routes I walk mainly in traffic calmed areas & $57 \%$ & $17 \%$ & $26 \%$ \\
On my everyday routes I choose green routes even if it means to & $35 \%$ & $21 \%$ & $44 \%$ \\
make a detour & & & \\
\hline
\end{tabular}


es: $71 \%$ (very) often experience that there was heavy car traffic, $56 \%$ (very) often walk in roads without green but with many parked cars, and $39 \%$ in roads where there are no seats/benches to rest on (see table 2). These experiences do certainly not reflect the expectations of an attractive route.

\section{Comparison - subjective safety vs. attractiveness}

The survey results indicated that greenery is important for active mobility. But does it really influence the attractiveness of streets? What kind of effect does it have on the subjective feeling of safety?

\section{Attractiveness}

In general, both roads did not get high scores for attractiveness. Only $6 \%$ of the respondents consider these streets 'attractive'. Some stated that these streets are 'rather attractive' which makes $20 \%$ for NG and 25\% for LS (see figure 3).

LS with greenery, however, scored significantly better than NG $\left(\chi^{2}(4)=19.76, p=.001\right)$. More than $50 \%$ consider NG an 'unattractive' street. 'Unattractiveness' in both streets includes: heavy car traffic, noise and the lack of greenery.

One third of the interviewee does not like walking in NG. In LS the share is significantly lower (13\%; $\left.\chi^{2}(4)=10.30, p=.036\right)$. Those who liked to walk in LS liked the many shops, the architecture and the greenery. In NG interviewees liked mainly the shops and restaurants.

$64 \%$ wouldn't like to 'sit on a bench' in NG. In LS significantly more people consider it likely to sit down on a bench $\left(41 \% ; \chi^{2}(4)=16.72, p=.002\right)$.

\section{Safety}

With respect to the subjective feeling of safety the results turned out to be the opposite way (see figure 4).

NG was rated significantly better than LS with respect to safety $\left(\chi^{2}(4)=22.88, p=.000\right) ; 50 \%$ feel
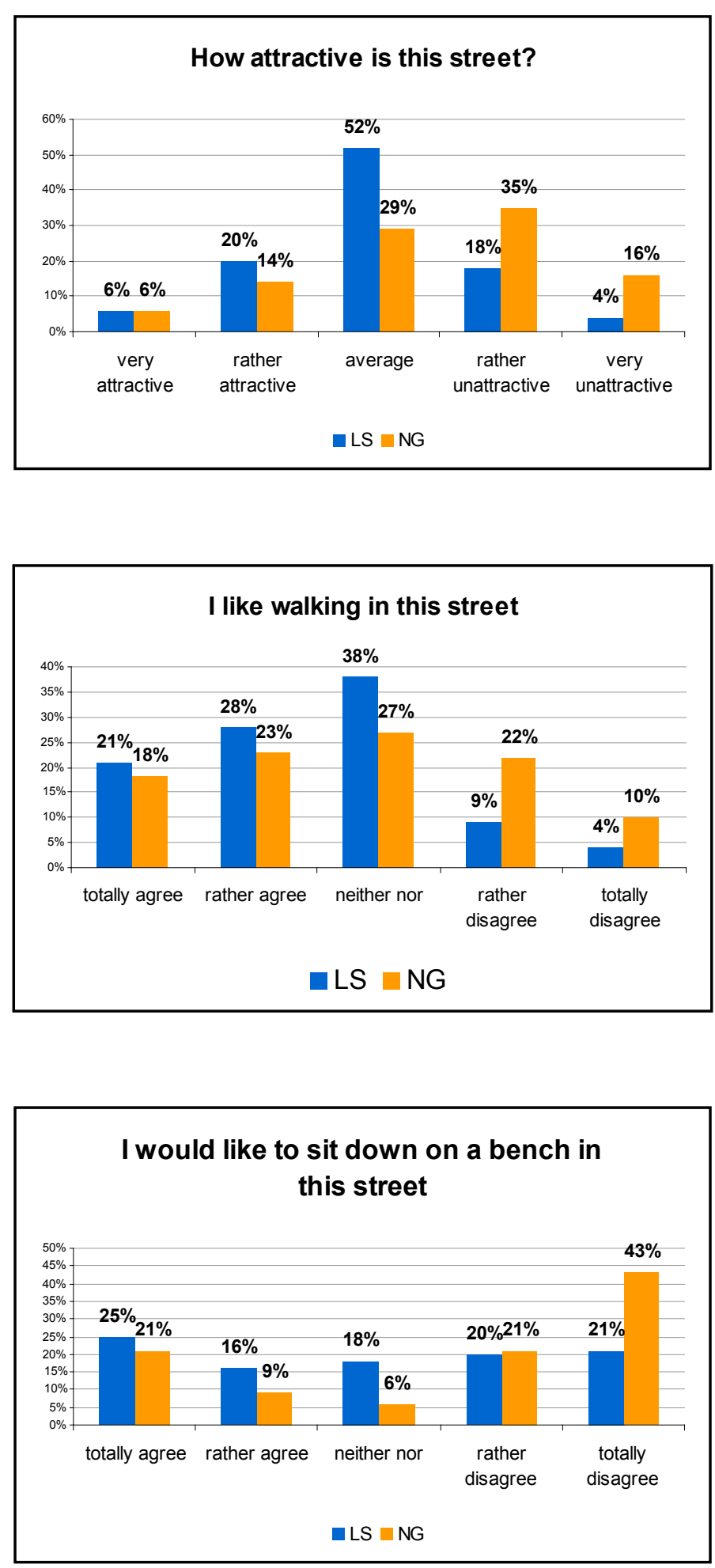

Figure 3: Attractiveness scores in LS and NG $(n=200)$

Table 2: Experiences in public space - Question: How often do you experience the following situations on your everyday walks? (very often - often - sometimes - rarely - never)

\begin{tabular}{lccc}
\hline Statement & Very often/often & Sometimes & Rarely/never \\
\hline Roads with heavy car traffic & $71 \%$ & $19 \%$ & $10 \%$ \\
Roads without green, but with many parked cars & $56 \%$ & $27 \%$ & $17 \%$ \\
Roads where there are no seats/benches to rest on & $39 \%$ & $25 \%$ & $26 \%$ \\
\hline
\end{tabular}


safe (as pedestrians) in NG. The share in LS is $24 \%$. $21 \%$ would let children walk on their own in NG and $11 \%$ in LS $\left(\chi^{2}(4)=7.66, p=.105\right)$. Car speeds are considered lower in NG than in LG $\left(\chi^{2}(4)=12.00\right.$, $\mathrm{p}=.017)$ but 'too fast' in both streets by less than $50 \%$ in NG and $56 \%$ in.

These results indicate that subjective feelings of safety seem not to correspond with greenery but rather with vehicle speed, which is lower in NG than in LS. 'Attractiveness' on the other hand seems to rather be linked to greenery and other infrastructural elements.
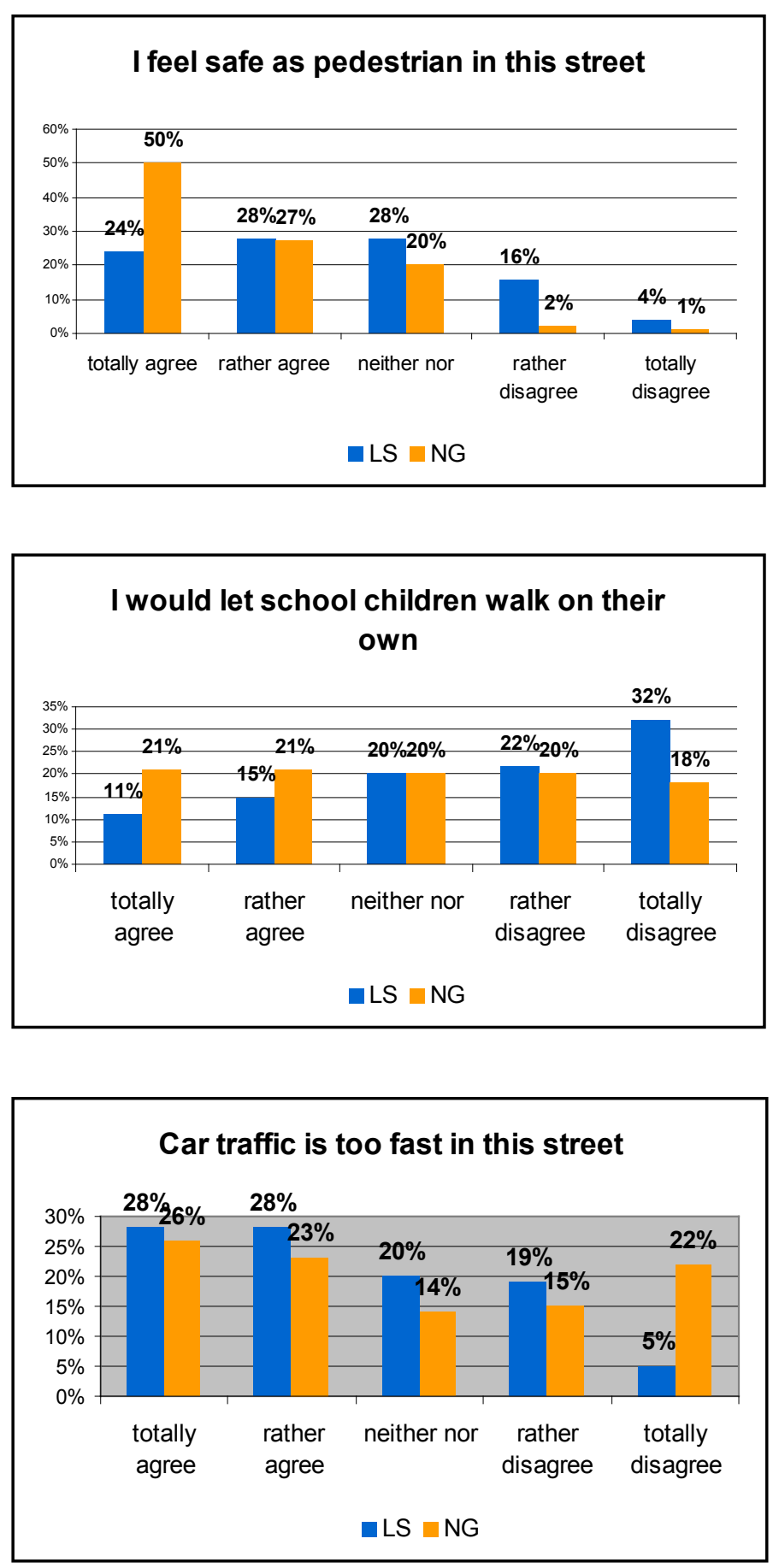

Figure 4: Safety scores in LS and NG $(n=200)$
The results with respect to safety and attractiveness are also underlined when comparing the results of those people who consider the roads as attractive. They significantly enjoy walking more than those who do not evaluate the roads as attractive $\left(\chi^{2}(16)=\right.$ $140.05, p=.000)$. However, there is no significant result with respect to safety $\left(\chi^{2}(16) 24.12=, p=.087\right)$. People considering the roads as attractive do not feel safer than those people who assess the roads as unattractive (see table 3).

Table 3: Attractiveness- Enjoyment of walking and feeling of safety

\begin{tabular}{lcc}
\hline Evaluation & Enjoy walking & Feel safe \\
\hline Road is attractive & $47 \%$ & $30 \%$ \\
neutral & $41 \%$ & $36 \%$ \\
Road is unattractive & $12 \%$ & $34 \%$ \\
\hline
\end{tabular}

\section{DISCUSSION AND CONCLUSION}

Greenery is considered as important aspect when walking and cycling. Especially elderly people, women and those who walk a lot value urban greenery. These target groups benefit the most if you make the city greener. You might not persuade car drivers by promoting attractive walking routes but if car drivers start walking because of other reasons greenery is an important aspect to make walking an enjoyable mode.

The readiness to make detours to reach a green route is low, especially among the car drivers. Green space planning and route planning should take this into consideration, when designing streets or planning routes. For instance, in navigation apps there should always be the option/suggestion of a possible detour of max $15 \%$ to choose a route with more green.

The survey underlined the necessity for a better cooperation between those responsible for city greenery (in Vienna "Stadtgartenamt) and the traffic planning departments. While traffic calming measures have the potential to increase the subjective feeling of safety, they do not automatically improve the attractiveness of the street. When it comes to greenery it is the other way around: attractiveness does not necessarily mean improved safety, for instance when one has to cross streets. If safe and attractive pedestrian routes are the goal, measures to both improve 


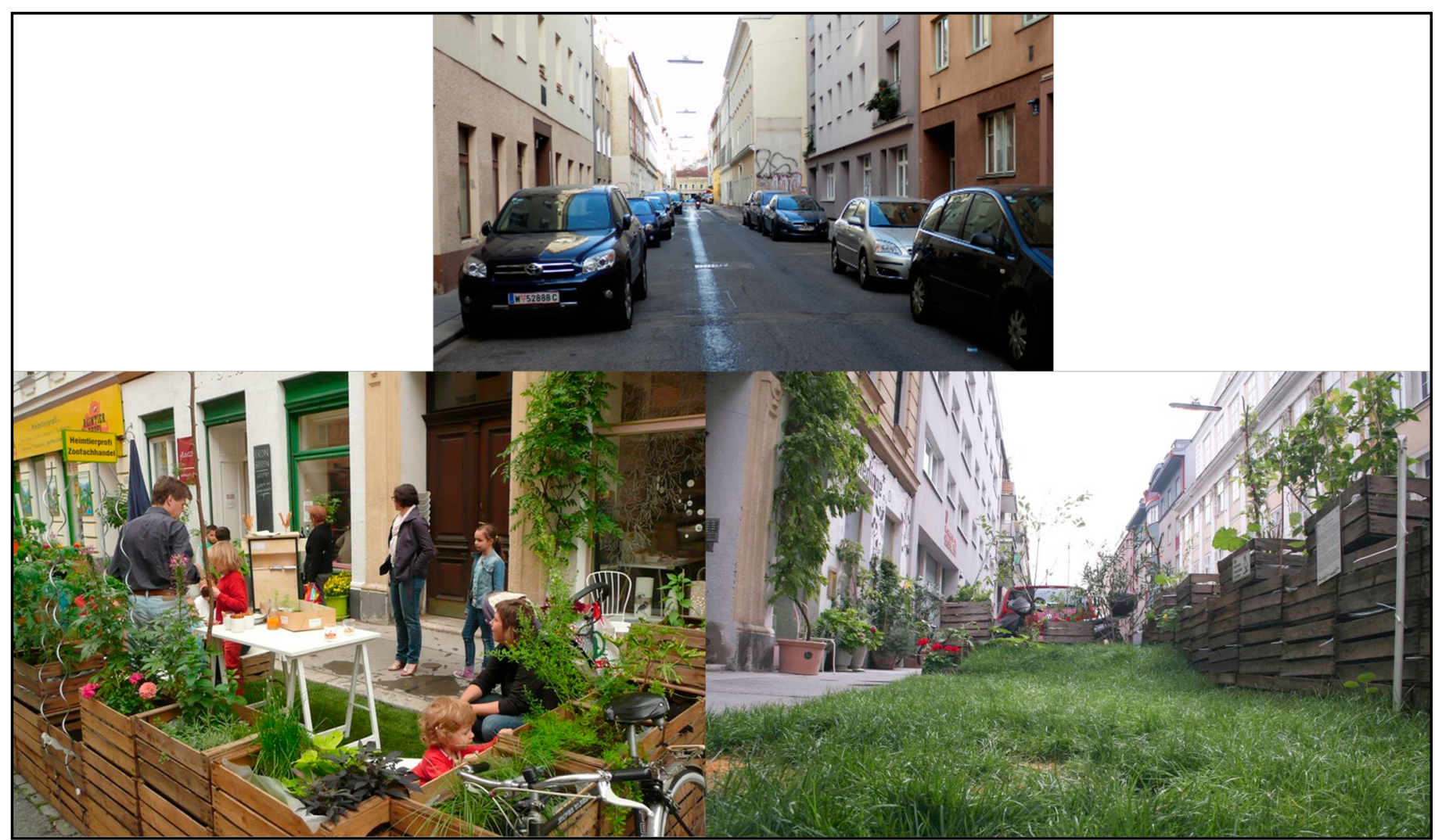

Figure 5: Krongasse in Vienna, 1050 and the Krongarden

http://www.krongarten.at/d7141_8xw/krongarten/

attractiveness - e.g. with the help of greenery - and subjective safety (lower vehicle speeds) need to be combined.

There are some nice examples of a successful combination of these two elements in the city of Vienna. One of them is the so called Krongarten (see fig. 5). The Krongarten is located in a traffic calmed area (Krongasse; $30 \mathrm{~km} / \mathrm{h}$ zone) in the inner city of Vi- enna. There used to be no green in this lane. A group of local artists decided to make the lane greener. In a long process they were allowed to make use of two parking spots for creating a green oasis. Since 2012 these two designated spots are designed and arranged by local residents during the summer time.

Such a procedure could make use of existing quality criteria. For instance, there are several national

\section{Table 4: Quality criteria active mobility \& greenery}

\section{Quality criteria according to Contribution of greenery \\ WALCYNG/ HOTEL}

Safety (subjective and objective)

Comfort

Aesthetic

Accessibility

Sustainability

Social Communication

Participation separation to cars - protection against accidents; protection against weather conditions (against sun, rain, wind); protection against harassment, lively streets prevent harassments Reduction of stress; traffic calming; broad sidewalks - accessibility

Increase of sojourning; eye catcher; experiences of nature perception of seasons; cleanliness and maintenance of walking infrastructure; noise and air pollution reduction

Barrier free; Design for all to attract different kind of target groups

Climate stabilising function; Prevention of large scale sealing

Inducement of activities and communication

"Community gardening" - promotion of communication and social contact Identification with the neighbourhood and the district

Prevention of vandalism by creating a sense of togetherness 
and international research projects that deal with quality criteria for walking (see e.g. Cost action 358, Methorst et al. 2010). In the Eu-Project Hotel (Bein et al. 2004) quality criteria were set up on basis of the EU-Project Walcyng (Hyden et al. 1997). These criteria could be applied for green space planning, too. The following table (4) gives an overview of these criteria and the relation to green space planning

In summary, the results of empirical work in the project GoGreen indicate that there is a clear relation between urban greenery and the share of active mobility. The trend to more urban green is noticeable not only in Vienna, but it is a worldwide phenomenon, as greenery has the potential to improve quality of life (see eg. Müller 2008, Acebillo 2012, Grün Stadt Zürich 2006). The changes in awareness can be identified in residents' interests and attitudes, and in the planning and administration. The idea of a car-dominated city is being gradually replaced by a human-centred planning approach. Experts stress the importance of more intersectoral exchange and cooperation between traffic planning and green planning departments on a macro-, meso- and micro level as the coordination between traffic departments and green space planning is scarce. There is, therefore, room for improvement. Moreover, interdisciplinary research on this topic is necessary.

A professional handling of urban greenery with respect to planting, care and maintenance is important for a lasting success. Urban greenery has a stimulating and enlivening effect if it is well-kept and a visible part of a holistic city concept.

\section{SHORT COMINGS OF THE STUDY}

It is obvious that the two streets that were chosen for a comparison are very different in many respects that all could have an impact on how attractiveness and subjective safety are perceived. Thus, a statistically thorough calculation of such impacts is out of the question. However, both places differ distinctly in two aspects that are important for our study: In one road there is nice greenery, while the speed limit is at $50 \mathrm{~km} / \mathrm{h}$, while in the other street there is no greenery, but a $30 \mathrm{~km} / \mathrm{h}$ limit leading to lower car speeds. In our opinion this makes it possible to at least attribute exploratory character to the study presented here. Considering the results, we conclude that it would make sense to carry out more research in order to compare the effects of car speeds and greenery, with more resources than those available to the authors of this study.

Acknowledgment: The project was funded by the Austrian Research Promotion Agency. It was carried out by FACTUM OG and MK Landscape architecture.

\section{REFERENCES}

Acebillo J. ( 2012) A new urban metabolism Barcelona / Lugano, Actar, New York, Barcelona

Adkins A., Dill J., Luhr G., Neal M. (2012) Unpacking Walkability: Testing the Influence of Urban Design Features on Perceptions of Walking Environment Attractiveness. Journal of Urban Design, 17(4), S. 499-510

Arnberger A., Eder R. (2012) The influence of green space on community attachment of urban and suburban residents. Urban Forestry \& Urban Greening, 11(1), S. 41-49

Bein N., Petica St., Plichtova J., Petrjánošová M., Risser R., Sardi G.M, Ståhl A. (2004) Final Report, of the EU-Project HOTEL: How to analyse Life Quality, an accompanying measure within the EU fifth Framework Programme Keyaction „Improving the Socio Economic Knowledge Base“; HPSE-2002-60057, Bratislava \& Vienna

Bowler D.E., Buyung-Ali L., Knight T.M., Pullin A.S. (2010) Urban greening to cool towns and cities: A systematic review of the empirical evidence. Landscape and Urban Planning, 97(3), S. 147-155

Weber C., Tschannen E., Winkler R., Graf S., Bähni I. (Eds.) (2006) Grün Stadt Zürich: Das Grünbuch der Stadt Zürich

Dinnie E., Brown K.M., Morris S. (2013) Community, cooperation and conflict: Negotiating the social well-being benefits of urban greenspace experiences. Landscape and Urban Planning, 112(1), S. $1-9$

Ehmayer C. (2015) Partizipative Aneignung des öffentlichen Raums am Beispiel des Wiener Donaukanals, in: Psychologie in Österreich Nr. 2 2015, S 140-146

Han B., Cohen D., McKenzie T.L. (2013) Quantifying the contribution of neighborhood parks to physical activity. Preventive Medicine, 57, S. 483-487

Hydén Ch., Nilsson A., Risser R. (1997) WALCYNG: Walking and Cycling instead of shorter car trips, Final report. Institute for Technology \& Society. University of Lund and FACTUM, Vienna

Knoflacher H. (1996) Zur Harmonie von Stadt und Verkehr. Freiheit vom Zwang zum Autofahren, Wien: Böhlau Verlag

Methorst R., Risser R., Sauter D., Tight M., Walker J. (2010) Cost 358 Pedestrians' Quality Needs. PQN Final Report

Müller (2008) Internationale Best Practices, Öffentlicher Raum und ruhender Verkehr, Wien: Im Auftrag der MA 19, MA $21 \mathrm{~A}$ und MA 18 
Mursch-Radlgruber E., Trimmel H. (2015) Räumlich und zeitlich hochaufgelöste Temperaturszenarien für Wien und ausgewählte Analysen bezüglich Adaptionsstrategien, Bericht 2. Teil, "Räumliche Differenzierunge der mikroklimatischen Eigenschaften von Wiener Stadtstrukturen und Anpassungsmaßnahmen”. Institut für Meterologie, Universität für Bodenkultur im Auftrag der Wiener Umweltschutzabteilung, MA 22 der Stadt Wien, S5-6

Nowak D.J., Crane D.E., Stevens J.C. (2006) Air pollution removal by urban trees and shrubs in the United States. Urban Forestry and Urban Greening, 4(3-4), S. 115-123

Peters K., Elands B., Buijs A. (2010) Social interactions in urban parks: Stimulating social cohesion? Urban Forestry \& Urban Greening, 9(2), S. 93-100

Tyrväinen L., Ojala A., Korpela K., Lanki T., Tsunetsugu Y., Kagawa T. (2014) The influence of urban green environments on stress relief measures: A field experiment. Journal of Environmental Psychology, 38, S. 1-9

Van den Berg A. E., Hartig T., Staats H. (2007) Preference for nature in urbanized societies: stress, restoration, and the pursuit of sustainability. Journal of Social Issues, 63, S. 79-96 